Edited by Kiriakos Xenitidis and
Colin Campbell
Contents
- Disclosure of religious beliefs
- Diagnosing chronic fatigue syndrome
experiences

\section{Disclosure of religious beliefs}

Surely after more than 200 years, psychiatry has become reasonably sophisticated and we can assume that there is no such thing as an unbiased comment. Professor Cooper's attack on Professor Casey for being 'a sincere member of the Roman Catholic Church $^{1}$ is only justified if he also states, as the Editor does, that the other comment comes from Dr Oates, who is a 'representative of the pro-choice group.' ${ }^{2}$ These senior psychiatrists were asked by the Editor to comment because they had both a special interest and special expertise.

There is a more general issue at stake here. It seems a sad reversion to attitudes in psychiatry of the 1960s when taking a religiously inspired position was seen as being unacceptably prejudiced, whereas taking a non-religious stance, even at the expense of the patient's discomfort, was regarded as normal practice. Professor Casey has been asked to wear her religious belief publicly, like some yellow Star of David, with the intention to undermine the validity of her professional opinion.

As a former chairman of the Royal College of Psychiatrists' Spirituality and Psychiatry Special Interest Group, I would hope that we could now give equal value to the viewpoints of psychiatrists with different philosophical and religious backgrounds. Dr Oates should be permitted, even in your august pages, to express a personal position, and so should Professor Casey. Yes, I do express a personal interest.

1 Cooper JE. Abortion and mental health disorders. Br J Psychiatry 2009; 194 570.

2 Tyrer P. Editor's note. Br J Psychiatry 2009; 194: 571

Andrew Sims, c/o Royal College of Psychiatrists, 17 Belgrave Square, London SW1X 8PG, UK. Email: ruth-andrewsims@ukgateway.net

doi: 10.1192/bjp.195.4.368

Cooper ${ }^{1}$ states 'we all start from a position determined in part by personal background, and readers will not fully understand comments unless such things are known', referring to Casey's ${ }^{2}$ commentary on Fergusson et $a l^{3}$ and her Catholic faith. This seems to suggest that however sound our reasoning may be, it must be taken with a pinch of salt because one is a Catholic. Perhaps a Black man's arguments against racism would be similarly invalid. No doubt Professor Cooper would not want an upsurge in anti-Catholic bigotry, but his suggestions may not prevent it.

1 Cooper JE. Abortion and mental health disorders. Br J Psychiatry 2009; 194 570.

2 Casey $\mathrm{P}$, Oates $\mathrm{M}$, Jones I, Cantwell R. Invited commentaries on .. . Abortion and mental health disorders. Br J Psychiatry 2008; 193: 452-4.
3 Fergusson DM, Horwood L, Boden JM. Abortion and mental health disorders: evidence from a 30-year longitudinal study. Br J Psychiatry 2008; 193 : 444-51.

Mark Blackwell, Sutton Home Treatment Team, Sutton General Hospital, Surrey SM2 5NF, UK. Email: mark.blackwel|@swlstg-tr.nhs.uk

doi: $10.1192 /$ bjp.195.4.368a

Professors Fergusson and Tyrer admirably address the scientific issues raised in the letter by Professor Cooper. ${ }^{1}$ However, one phrase remains of concern: Professor Casey's personal religious faith is declared by Professor Cooper. Should the public declaration of someone else's religious faith by a third party be encouraged? If a person wishes to 'come out' publicly about their faith as part of a publication, perhaps that is acceptable, or perhaps a scientific international journal is not the appropriate forum for the exposé of such matters?

1 Cooper JE. Abortion and mental health disorders. Br J Psychiatry 2009; 194: 570.

Katherine J. Aitchison, MRC Social, Genetic \& Developmental Psychiatry Research Centre, Institute of Psychiatry, King's College London, PO80, 16 De Crespigny Park, Denmark Hill, London SE5 8AF, UK. Email: katherine.aitchison@kcl.ac.uk

doi: 10.1192/bjp.195.4.368b

Author's reply: I am very pleased to have the opportunity to respond to the letters of Drs Blackwell and Aitchison, and Professor Sims. They are all relevant to the important general issue of whether authors of papers on topics known to be controversial (such as abortion and ethnicity) should always be obliged to state their own background position in full. I suggest that the answer to this must always be 'Yes, definitely.'

In scientific research, all possible attempts should be made to keep biases to a minimum, but unavoidable human influences can still be there and need to be known by readers if they are to understand both the data and the conclusions. These include the reasons for the research or review, the conclusions of any previous related studies by the same authors, possible biases in the methods of collection and analysis of the data, and possible biases in the conclusions of the authors. Different readers may then interpret the findings in different ways, depending upon their own viewpoint. If authors of papers on controversial topics follow these guidelines, and always state whether their conclusions are based solely upon the data of the study or also upon other background personal reasons, then the question of 'outing' will never arise. Similarly, on this line of reasoning, the simple statement of undisputed facts should not be regarded as 'an attack'. There is wide agreement that financial rewards in the background must always be declared, so surely the same should apply to other potentially biasing influences.

Professor Sims's reference to the 'psychiatry of the 1960s' puzzles me, and without specific examples I cannot comment on this.

The overall point at issue is that readers should be able to make up their own minds, and not be limited only to what the authors believe to be the best interpretation of the study. This may be rather perfectionist advice, but at least it gives a model as a target.

A more specific issue relates directly to the paper by Fergusson et $\mathrm{al}^{1}$ and to the comments by Professor Casey suggesting that this study constitutes evidence that special emphasis on the potential psychiatric hazards of abortion should be an obligatory part of psychiatric educational programmes.

Drs Rowlands \& Guthrie ${ }^{2}$ seem to me to give a good summary of this whole problem: 'Whether abortion causes harm to women's 